\title{
Spatial distribution patterns of scorpions (Scorpiones) in the arid Pilbara region of Western Australia
}

\author{
Erich S. Volschenk ${ }^{1,3}$, Allan H. Burbidge ${ }^{2}$, Bradley J. Durrant ${ }^{1,2}$ and Mark S. Harvey ${ }^{1}$ \\ ${ }^{1}$ Department of Terrestrial Zoology, Western Australian Museum, Locked Bag 49, Welshpool DC, \\ Western Australia 6986, Australia. \\ ${ }^{2}$ Department of Environment and Conservation, PO Box 51, Wanneroo, Western Australia 6065, Australia. \\ ${ }^{3}$ Subterranean Ecology Pty Ltd, Suite 8/37 Cedric Street, Stirling, Western Australia 6021, Australia. \\ Email: evolsche@gmail.com
}

\begin{abstract}
We sampled scorpions in a systematic survey of 294 sites representing the major landform types across the arid Pilbara region of north-western Australia, an area of ca. $179,000 \mathrm{~km}^{2}$. We trapped two species of Isometroides, 10 of Lychas and 10 of Urodacus. All species were undescribed except one ( $U$. megamastigus). Patterns of occurrence were similar to those found previously in arid Western Australia, in that temperature and soil characteristics seem to influence scorpion distributions; however, there were only weak correlations between species richness and sandiness of the soil, water availability, and annual temperature. In a classification of the sample sites based on occurrence of scorpion species, the major division in the dendrogram was associated with topographic and soil variables, while annual temperature, soil depth, ruggedness, total $\mathrm{K}$ and the presence of Acacia species were the five variables (of the 25 available) providing the best fit with the site matrix. Much more information about the biology and ecology of individual species will be needed in order to interpret these patterns confidently.
\end{abstract}

Key Words: Biogeography, Buthidae, Lychas, Isometroides, Urodacidae, Urodacus, arid uplands

\section{INTRODUCTION}

Scorpions are important components of arid ecosystems because their levels of diversity and abundance mean that they contribute significantly to the biomass of animal assemblages (Polis 1993), as well as being important predators and prey for other species (e.g. Main 1956; Koch 1970; Polis 1991). While scorpions have low metabolic rates (Withers and Smith 1993; Lighton et al. 2001), restricting their role in energy and nutrient cycling, their relatively high biomass and role in food webs mean that they may play an important part in structuring the communities in which they occur (Polis and Strong 1996; Ayal 2007).

Despite their importance in arid ecosystems, little is known about the factors that influence species richness and composition. Relatively few studies on scorpions have been undertaken at a regional level greater than $10,000 \mathrm{~km}^{2}$ and most of these have focused on taxonomic diversity and historical biogeography, e.g. Lamoral (1979), Namibia; Koch (1977, 1981), Australia and New Guinea; MelloLeitão (1945), Venezuela; Tikader and Bastawade (1983), India; Levy and Amitai (1980), Israel. These contributions also represent syntheses of many previous studies, compiled into single volumes. From a biogeographic perspective, one of the more interesting broad-scale studies is that by Prendini (2005), who identified areas of species richness and endemism in southern Africa and related these patterns to broad-scale landform elements and presumed phylogeny. Studies of scorpions and their distributions in smaller areas (less than 1,000 $\mathrm{km}^{2}$ ) are more common, but predominantly aim at understanding scorpion community dynamics, ecology and ecophysiology (Hadley 1990; Polis 1990; Smith 1991; Locket 1993).

Scorpions are famous for their associations with deserts and ability to tolerate generally higher temperatures than other arthropods; however, most desert scorpions avoid extremely high temperatures by retreating into burrows, deep rock crevices, under leaf litter or other surface debris (Hadley 1990; Polis 1990).

Geological history has been invoked to explain scorpion diversity patterns in Baja California, but ecological constraints have been hypothesised for the patterns of scorpion species richness and 
occurrence on the Italian peninsula, although the relevant ecological parameters were not determined (Due and Polis 1986). Elsewhere, various environmental parameters have been used to explain scorpion distribution, species richness or composition. For the endemic Australian scorpions, Koch (1981) suggested that historical factors had produced a pattern of southern, central and northern species, the non-endemics occurring mostly in a northern to eastern coastal area and an eastern to southern area east of the Great Dividing Range. Koch (1981) proposed rainfall, temperature and possibly competition to explain the distributions of individual species, but noted that vegetation type did not appear to be very important.

Durrant et al. (2010) found that geological history appears to be a factor in the distribution of spiders in the Pilbara region of north-western Australia, and Guthrie et al. (2010) found similar patterns for ground-dwelling beetles. In both these studies, contemporary environmental factors were also important in influencing species richness and composition.

Surveys of invertebrate diversity, particularly short-range endemic species (species naturally restricted to distributions of $\leq 10,000 \mathrm{~km}^{2}$; Harvey 2002; Ponder and Colgan 2002), are an important aspect of environmental management in Western Australia. In recent years, interest in the invertebrate composition of the Pilbara region has increased, due almost entirely to the acknowledgment of threatening processes to restricted species from a rapidly growing resource industry. One of the greatest challenges to the management of shortrange endemic invertebrates is the lack of regional context on which to base particular biological finds, and this is especially so in the Pilbara region of Western Australia. Because scorpions, burrowing species in particular, are generally sedentary and sometimes have narrow physiological or ecological tolerances (Polis 1990), they may be useful in biogeographical studies, although this potential has not been seen to date in regional studies in Australia (Smith and McKenzie 2000).

The purposes of this study were to examine diversity and distributions of the scorpions captured during a large regional survey of the Pilbara region and to determine the relationship between distribution patterns and a range of

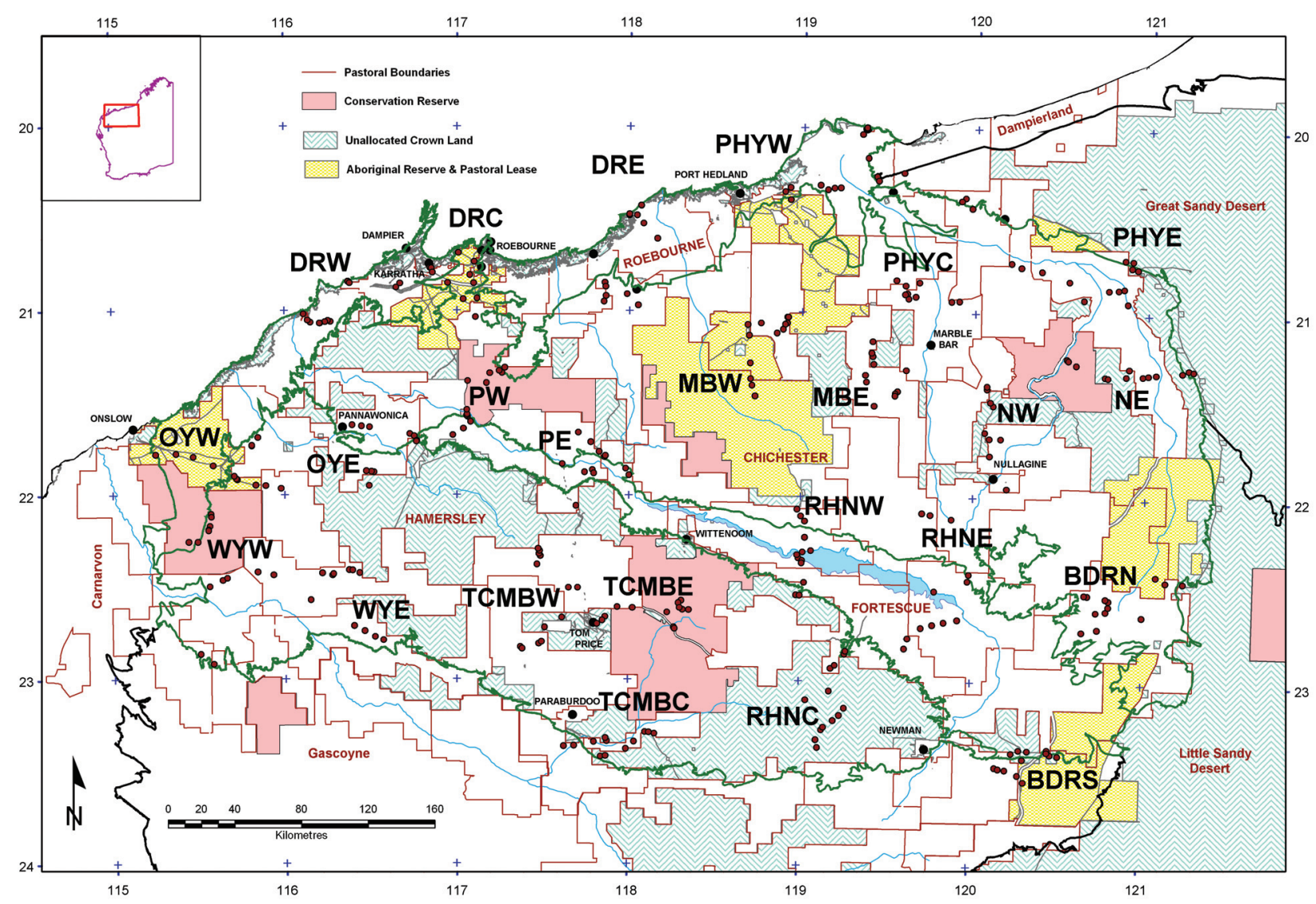

Figure 1 The Pilbara Biogeographic Region (Department of Environment Water Heritage and the Arts 2009) showing quadrat locations (red dots), towns (black dots), main rivers (blue lines), land tenure (shading, see map key), IBRA sub-regions (green lines), and surrounding IBRA regions (black lines). The 24 survey areas are shown by their abbreviated codes - see McKenzie et al. (2009) for further detail. 
environmental parameters. The parameters used were those available from a broader biogeographic survey (McKenzie et al. 2009), but some were thought to be of relevance to scorpions (e.g. Polis 1990). Specifically, we hypothesised that both species richness and composition would be related to sandiness of the soil, water availability (Fet et al. 1998; Smith and McKenzie 2000) and, perhaps, to temperature (Brown et al. 2002).

\section{METHODS}

\section{Study area}

The study area conformed very closely with the extent of the four IBRA (Interim Biogeographic Regionalisation of Australia) subregions (Thackway and Cresswell 1995) overlying the Pilbara Craton (Figure 1). The Pilbara Craton is one of Australia's major geological blocks (Trendall 1990), with landscapes structured by hard rocks laid down in Archaean times 2.5 to 3.5 billion years ago-some of the oldest exposed rocks on Earth. Most of the landscape is either rocky or colluvial, although the coastal plains are predominantly alluvial close to river outflows. Vegetation in the Pilbara consists mostly of tree- and shrub-steppe communities with Eucalyptus trees, Acacia shrubs and hummock grasses such as Triodia pungens and T. wiseana (Beard 1990). The region has an arid tropical climate (Beard 1990; Leighton 2004). Maximum temperatures often reach more than $40^{\circ} \mathrm{C}$ in the hottest part of the year (November-March), while in winter the maximum temperatures fall to about $25^{\circ} \mathrm{C}$. Rainfall is low and variable, with average annual rainfall ranging from about 200 to $350 \mathrm{~mm}$, and average yearly evaporation greatly exceeds average yearly rainfall. The area is subject to occasional tropical cyclones, usually between January and April. More detailed overviews of the study area are provided elsewhere (Burbidge et al. 2006; McKenzie et al. 2009).

\section{Sampling}

As part of a wider survey to determine broadscale biogeographic patterns in the Pilbara region (McKenzie et al. 2009), the study area of ca. 179,000 $\mathrm{km}^{2}$ (Figure 1) was divided into 24 survey areas. These were positioned to allow sampling across the extent of the study area, and across all likely environmental gradients, in an efficient manner. Twelve or thirteen quadrats, each $50 \times 50 \mathrm{~m}$, were positioned to sample the geomorphic profile of each survey area, with a total of 294 quadrats. We positioned quadrats in the least-disturbed examples that we could find in each habitat type. Most quadrats were pseudo-replicated in the other survey areas to allow for the internal heterogeneity of the stratification units and to minimise any analytical circularity introduced by stratification (Taylor and
Friend 1984; McKenzie et al. 1989). Further details concerning quadrat selection, and quadrat locations, are provided in McKenzie et al. (2009).

The objective of sampling was to determine species presence/absence at each quadrat. No attempt was made to estimate species abundance, as pitfall traps are not regarded as a reliable technique for this purpose because of the reliance on the activity of the animals, which can vary greatly between species (Standen 2000).

Twelve survey areas were established and pitfall traps opened mid-2003 and closed late-2004, while the remaining 12 survey areas were sampled between mid-2005 and late-2006. In each sampling period, sites were sampled from across the extent of the Pilbara bioregion, to minimise possible effects of year to year climatic variation. The average length of sampling across all quadrats was 395 days each. The 12-month trapping period allowed for the full sampling of all seasons, and reduced the suspected bias that may occur in restricted sampling periods. The sampling rationale, design and logistics are further explained in McKenzie et al. (2009).

One wet pitfall trap was positioned just outside each corner and one in the centre of each quadrat. The total number of traps was therefore 1490, and they operated for a total of approximately 590,000 trap nights. Each trap consisted of a twolitre, UV-resistant plastic container $(80 \mathrm{~mm}$ neck diameter) inserted into a PVC sleeve dug into the ground, flush with the ground surface. To form a continuous surface between the ground and jar lip an acrylic annulus covered in glued sand was attached between the PVC sleeve and jar lip. Two hoop iron stands fitted between the PVC sleeve and jar were used to hold a $200 \times 200 \mathrm{~mm}$ Colorbond(C) (corrugated steel) roof approximately $4 \mathrm{~cm}$ above the ground surface. The aim of the roof was to reduce unwanted by-catch, but it also reduced accumulation of leaf litter, etc., resulting in cleaner samples. Each pitfall trap contained one litre of preserving fluid (ethylene glycol with $4 \%$ formalin). To minimise possible effects of traps accumulating soil or debris, or drying out, samples were collected from all traps at least once during the middle of the trapping period, and then again at the end of the 12 month period. Samples were returned to the laboratory, washed in water and stored in $75 \%$ ethyl alcohol until sorting, processing and identification. Most of the data records of Urodacus are based on the recorded occurrence of adult male specimens, as there are difficulties in the identification of female and juvenile scorpions in the genus. Lychas and Isometroides were identified from male, female and subadult specimens. While all captured specimens were retained and deposited in the Western Australian Museum, scorpions belonging to the genus Isometroides were excluded from 


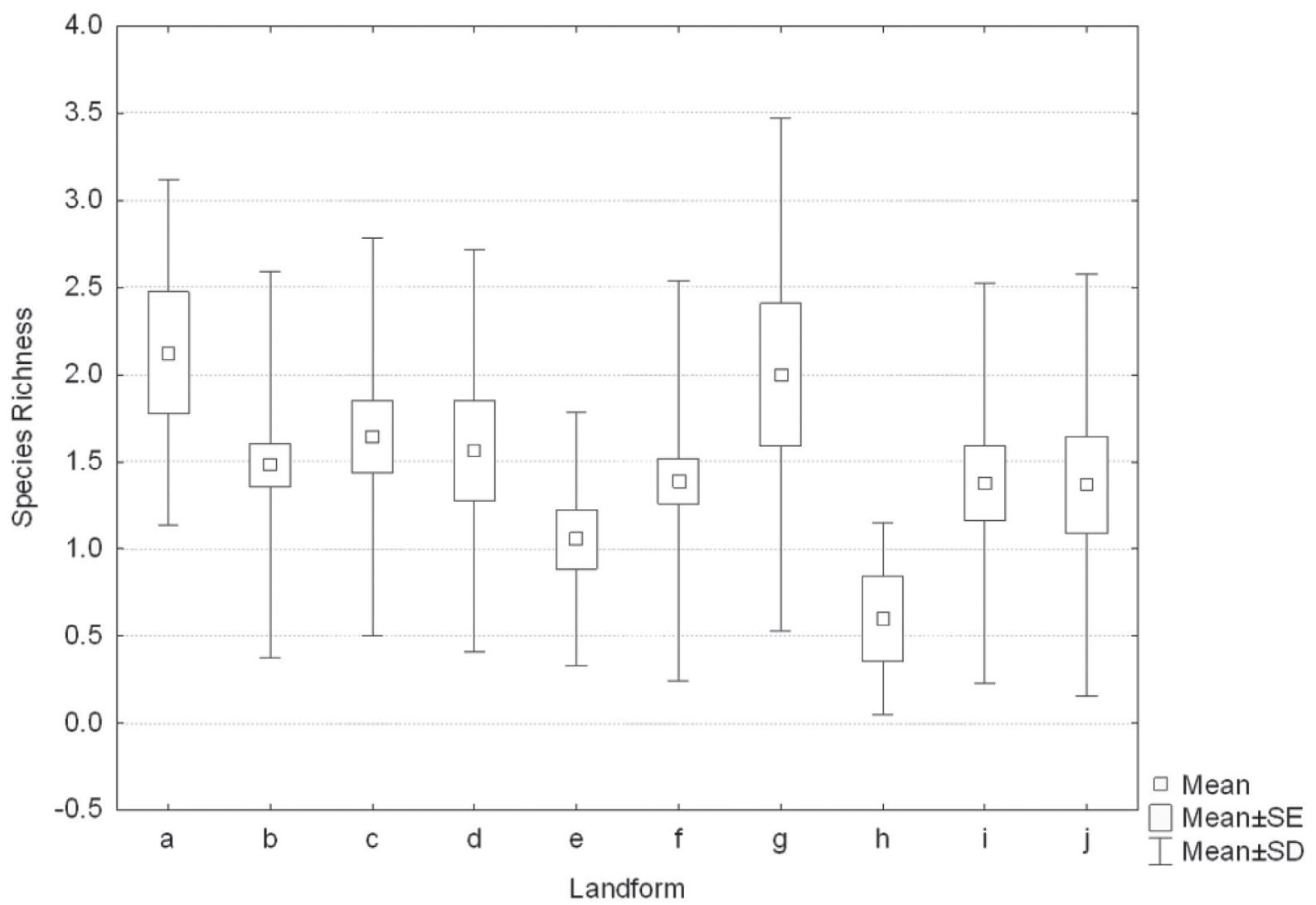

Figure 2 Species richness by landform category. Key to categories: a = granite hills (scorpions encountered at 7 of the 8 sites in this category); $\mathrm{b}=$ massive rocks of hilltops and scree slopes $(63 / 81) ; \mathrm{c}=$ flat stony uplands, slopes and plains with shallow soils $(<0.5 \mathrm{~m})$ over pavement or hardpan $(27 / 31) ; \mathrm{d}=$ calcrete or opaline hills and mesas (13/16); e = heavy cracking/heaving clay plains and very gentle slopes $(14 / 18) ; \mathrm{f}=$ deep clayey profiles, often with surface strew and/or stony profile $(60 / 77) ; g=$ granitoid slopes or plains with gritty clay profile mantling sheet granite at depth $(11 / 13) ; \mathrm{h}=$ saline mud with samphire, sometimes mixed with Buffel (Cenchrus ciliaris) or Triodia where thin sandy surface present (3/5); i = deep sand and/or firm (slightly clayey) sand as dunes and plains, desert as well as beach sands $(22 / 29) ; j=$ riverine levees, riverine beds, or clay pans with River Gums and/or paperbark trees (15/19). For further details of landforms see Appendix D in McKenzie et al. (2009).

the analysis because they may not be readily captured by the methods we used (E.S. Volschenk, unpublished data). We caught only four specimens (representing two species) of Isometroides, all from different quadrats.

\section{Taxonomy}

The scorpions of the Pilbara are poorly known, but in this survey we recorded species from two families, Buthidae and Urodacidae. The taxonomy of both families is problematic and under review, and the representatives of both are dominated by undescribed species. For the purpose of this study, morphospecies are used where species are clearly different from those currently known. We adopt the phylogenetic species concept whereby species constitute populations of organisms that can be consistently diagnosed from one another on the basis of somatic characters (Cracraft 1983,
1986, 1992). All of the scorpions sampled during this survey were vouchered and deposited in the Western Australian Museum.

\section{Analyses}

The analytical approach taken was an exploratory design based on the assumption that spatial distribution reflects an underlying correlation with environmental factors (Austin 1991), rather than meta-community interactions. A range of climatic, geomorphic, soil and vegetation attributes was derived for each quadrat; the full range, and the way in which they were measured or estimated, is described by McKenzie et al. (2009). Eighteen climatic attributes were derived for each quadrat using ANUCLIM (McMahon et al. 1995). These comprised annual and seasonal average and range values for temperature and precipitation. Soil geochemical variables were determined from bulked sub-samples 
collected across each quadrat. Quadrats that were significantly disturbed (predominantly from fire or flood) between quadrat selection and the end of the sampling period were removed from the data set, leaving a total of 294 quadrats that could potentially be included in the analysis.

The first step in the analysis was to assess the data for spatial autocorrelation; i.e. determine whether locations close to each other exhibited more similar values (lists of species present) than those further apart (Dormann et al. 2007). To test for this, we used PATN (Belbin 1993) to generate an association matrix based on Euclidean distance between sites, and converted this to a linear vector. Similarly, we took the Bray-Curtis matrix (based on scorpion occurrences at the same sites) and converted this to a linear vector. Plotting one vector against the other provides a scatter plot in which the slope of the line of best fit is a measure of spatial correlation, with a slope of zero indicating a complete absence of correlation (see Burbidge et al. 2010). In this case, the line was represented by the equation $\mathrm{Y}=0.6848+0.0001 \mathrm{X}$, indicating a small but detectable degree of correlation. We tested the significance of this using a randomisation test (the RELATE module in PRIMER) (Clarke and Gorley 2006). This gave a value of rho (0.056) that fell just within the upper range of values derived from 999 permutation tests, suggesting that there is little, if any, match between the Bray-Curtis and the distance matrices (the null hypothesis is that there is no match in spatial pattern, and so if there were a strong match, the observed value of rho would be outside the distribution from the permutation tests). Because the likely effects were so small, we did not correct for them in subsequent analyses.

The data matrix comprised the presence and absence of species on each quadrat. The computer package PATN (Belbin 1993) was used to reveal patterns in species composition in this matrix. The association measure 'Two-step' was used to determine the quantitative relationship between each pair of species, and the Bray-Curtis measure was used to compare the quadrats according to their species similarities. The dendrograms derived from these association matrices were derived using a modified 'unweighted pair group arithmetic averaging' (UPGMA) hierarchical clustering strategy (Sneath and Sokal 1973). In order to facilitate interpretation of both classifications, a two-way table was constructed from the classifications of sites and scorpions. Interpretation of the site analysis was assisted by the use of univariate plots of variables by site group, ranked on the basis of Kruskal-Wallis values.

To assist in the exploration of possible relationships between environmental variables and the site matrix, we used the BEST routine in PRIMER (Clarke and Gorley 2006). The site matrix was derived using the Bray-Curtis measure with a 'dummy' variable added, because of the high incidence of zero values in the matrix (Clarke et al. 2006). We used normalised values of a subset of 25 of the available environmental variables, chosen according to their inter-correlation values (Burbidge et al. 2010) and created a Euclidean distance matrix for comparison with the site matrix. The analysis was limited to the five 'best' variables, and the global match test utilised 99 permutations.

\section{RESULTS}

\section{Species richness and diversity}

The Pilbara buthids are represented by two genera, Lychas C.L. Koch and Isometroides Keyserling, and 12 species, none of which could be attributed to currently recognised species. Lychas was represented by 10 morphospecies while Isometroides was represented by only two species. The family Urodacidae was represented by 10 species in the genus Urodacus Peters, of which only one species is described: Urodacus megamastigus L.E. Koch.

\section{Lychas (Buthidae)}

The genus Lychas is the most widely distributed scorpion genus in Australia, with species recorded from virtually all of the Australian mainland. The genus has not been recorded from Tasmania. Four species of Lychas are currently recognised in Australia (Fet and Lowe 2000), but significant diversity is being uncovered by ongoing taxonomic work on the genus in Australia (E.S. Volschenk unpublished obs.). All of the known Australian Lychas species are endemic; however, members of this genus are also known from Africa, India, Southeast and Eastern Asia, making it one of the world's most widespread scorpion genera (Fet and Lowe 2000). In Australia, Lychas species are active, groundforaging scorpions that seek refuge in low bushes, under leaf-litter and logs or under the bark of trees during the day (E.S. Volschenk unpublished obs.).

\section{Isometroides (Buthidae)}

Only two species are presently recognised in the genus Isometroides (Fet and Lowe 2000). This genus is known from a wide distribution across semi-arid and arid northern Australia. Unlike Lychas, the genus is endemic in Australia (Fet and Lowe 2000). Isometroides have rarely been found in abundance in any habitat (Main 1956), which may be related to the feeding specialisation on ground spiders, observed by Main (1956). Isometroides is the only member of the Buthidae known to exhibit predatory specialisation. 


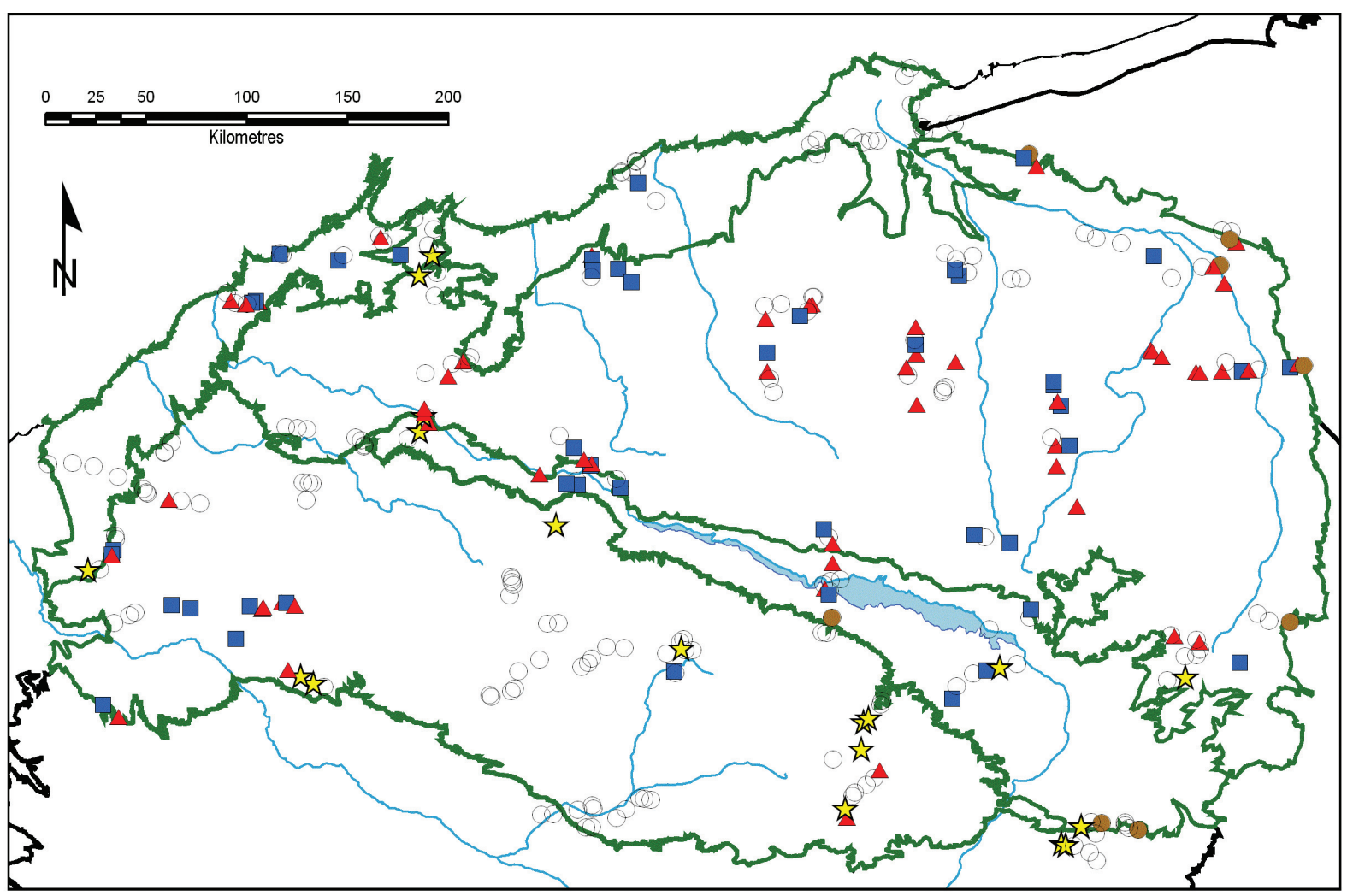

Figure 3 Distribution of the four-group partitions in the site classification. Empty circles (173) are sites that were not included in the analysis because no scorpions were caught at the site, or because any captures at the site were of 'singletons' (i.e. less than two species caught at the site; see text). Solid brown circles = Group $1(\mathrm{~N}=8)$, blue squares = Group 2 (45), red triangles = Group 3 (53), yellow stars = Group 4 (18).

\section{Urodacus (Urodacidae)}

The genus Urodacus is endemic in Australia and currently 22 valid species are recognised. Many more species are known. Diversity appears to be greatest in arid Australia. Most Urodacus species live in spiralling burrows in the ground and less frequently in shallow scrapes under logs and rocks, but a few specialist rock-dwelling species live in deep rock cracks. Foraging activity is highly centred around the burrow, and animals seldom appear to move beyond a body length from the burrow entrance. The exception to this is when adult males seek out mates, in which case they appear to abandon their burrows and forage widely. This mate-seeking activity is most intense on hot, humid nights following significant rains. In the Pilbara, this is a highly localised phenomenon reflecting the highly irregular and patchy rainfall pattern of the region. Species of Urodacus appear to be very longlived, with $U$. manicatus Pocock (a small species from relatively mesic forests) living as long as nine years (Smith 1966), and U. yaschenkoi Birula (a relatively large, arid-adapted species) living to 25 years (Marples and Shorthouse 1982).

We trapped 20 taxa of scorpions (ignoring Isometroides; see Methods) at a total of 235 quadrats; i.e. no scorpions were trapped at 62 quadrats. The data matrix is provided in Appendix 1,

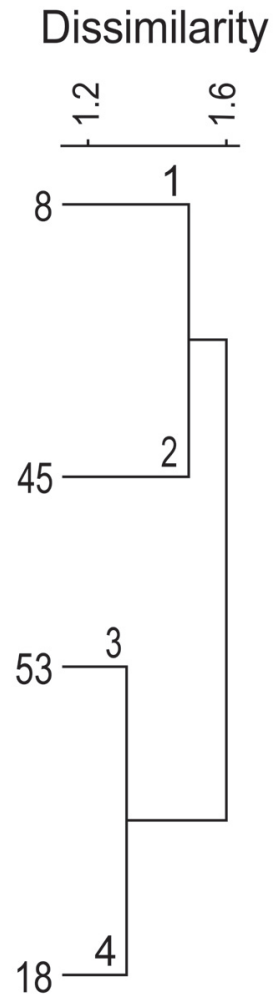

Figure 4 Four group site classification of the 124 sites in the Pilbara region, based on the presence of scorpion species. Numbers on the figure are group numbers (see text); numbers to the left are the number of sites in each group. 
Rug500

$\begin{array}{cc}K W=27.881 \\ \text { Group } & \text { Mean } \\ 1 & 2.22 \\ 2 & 3.13 \\ 3 & 7.65 \\ 4 & 11.5\end{array}$

\begin{tabular}{l}
$1.0 \quad 34.8$ \\
\hline
\end{tabular}

soil[

$K W^{\prime}=18.661$

Group Mean

$1 \quad 64.3$

$2 \quad 32.8$

320.1

426.8

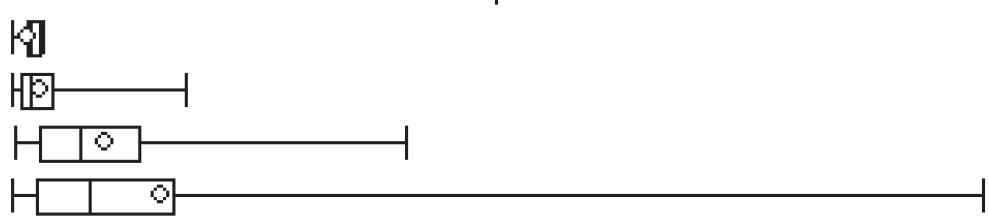

Tann

$\begin{array}{cc}\text { KW } & =11.314 \\ \text { Group } & \text { Mean } \\ 1 & 25.4 \\ 2 & 25.5 \\ 3 & 25.5 \\ 4 & 24.5\end{array}$
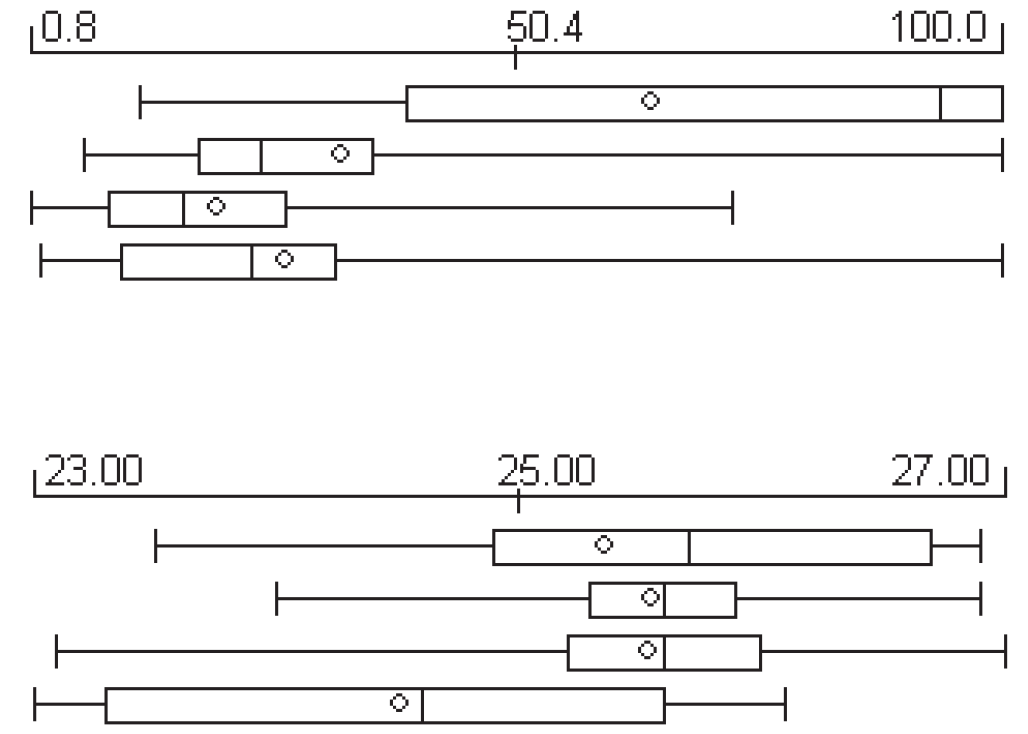

Figure 5 Differences between site groups in terms of various environmental parameters measured or estimated for each site, for the four quadrat groups defined in Figure 4. Other variables with relatively high Kruskal-Wallis values included Outcrop $(\mathrm{K}-\mathrm{W}=18.7)$, Sand $(15.7)$, exCa (14.8) and precipitation in the coldest quarter (14.3) but are not shown as they all displayed the same pattern as soil depth, or the inverse of that pattern. KW = Kruskal-Wallis value, obtained from PATN.

downloadable from the journal's website. For those quadrats where scorpions did occur, the number of species per quadrat varied from one to five (mean $1.8 \pm 0.95 S D)$; including quadrats where no scorpions were sampled, the mean was 1.5 species $( \pm 1.1 S D)$. Lychas sp. 2 was the most widespread species, being trapped at 99 quadrats, and L. sp. 4 was at 82; no other species was found at more than 50 quadrats. Two species were trapped at only one quadrat (L. sp. 7 at quadrat TCMBC05 and Urodacus megamastigus at PW08). These latter two species were removed from subsequent analyses, as occurrence at a single site provides little information about regional biogeographic patterns. There were 110 sites where only one species was encountered. Removal of sites with only one species and subsequent removal of species occurring at only one site (which also removed Lychas sp. 9 from the data set) resulted in a data matrix of 17 species by 124 sites. It is this matrix that was used for subsequent pattern analyses.

When sites were broadly categorised by substrate
(McKenzie et al. 2009), there were no clear differences in scorpion species richness across these broad types, with rocky substrates having a mean of 1.6 \pm 1.1 $S D(\mathrm{n}=135)$, sandy sites $1.4 \pm 1.2 S D(\mathrm{n}=48)$ and clayey sites $1.4 \pm 1.1(\mathrm{n}=114)$. Species richness did not vary greatly across landforms (Figure 2), except that there was a tendency towards higher species richness on landforms with a granitic substrate (landforms ' $a$ ' [granite hills] and 'g' [granitoid slopes or plains with gritty clay profile mantling sheet granite at depth]), and species richness was lowest on saline muds with samphire (landform ' $h$ '). These data must be interpreted with caution, however, because the sample sizes are small. In the southern part of the Pilbara, in the Hamersley uplands, there was a concentration of sites where we caught one or less species of scorpion, but there were few such sites in the Chichester block to the north, where granitic surfaces are more common (Figure 3).

We found only very weak correlation between sandiness of the soil, water availability or 


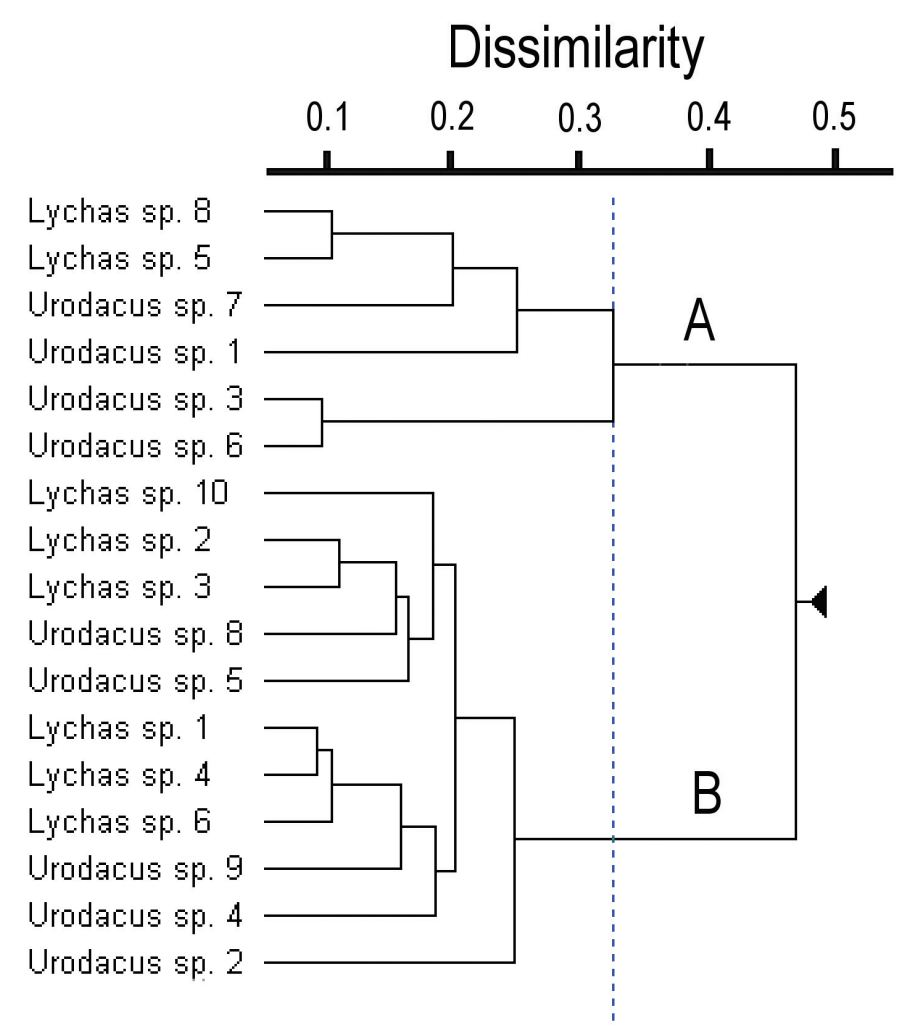

Figure 6 Classification of the 17 scorpion species captured in the Pilbara region, based on the quadrats at which they occurred.

temperature and species richness: sandiness $(\mathrm{Y}=$ $0.006 X+1.0 ; R^{2}=0.007$ ), silt (one possible surrogate for water availability) $\left(Y=-0.01 X+1.6 ; R^{2}=0.009\right)$ or annual temperature $\left(\mathrm{Y}=0.01 \mathrm{X}+17.9, R^{2}=0.004\right)$.

\section{Site classification}

Four groups of sites could be recognised in the dendrogram, resulting from classification of the sites in terms of scorpion species composition (Figures 3 and 4). The first major division in the dendrogram was between the 53 sites of Groups 1 and 2, and the 71 sites of Groups 3 and 4 . These two major site groupings differed strongly in terms of ruggedness, and to a less extent in the presence of outcrops, soil depth, sandiness and nutrient levels (Figure 5). At the four group level, Group 1 sites had lower nutrients and silt levels (and more sand), and were less rugged with deeper soils and lower dry season precipitation than the other site groups. These sites were primarily on the eastern margin of the study area (Figure 3), some of them being just outside the Pilbara IBRA region, in the adjacent desert. Two of these sites were on sand dunes, one was a sandy river bank, and the remaining five were sandy plains or gently sloping outwash fans. Groups 2 and 3 were both widespread in the Pilbara (Figure 3). Sites in Group 2 were less rugged than those in Groups 3 or 4 and had greater soil depth than Group 3 sites. Group 4 sites were in the most rugged areas, were mostly in the southern part of the study area and were cooler than the remainder (Figures 3 and 5). Relationships with environmental variables, however, were weak. The BEST routine identified annual temperature, soil depth, ruggedness, total $\mathrm{K}$ and presence of Acacia species as the five variables providing the best fit with the site matrix. The global match test gave a low $\rho$ value of 0.156 , and a significance level of $4 \%$, indicating that there was poor match between the environmental variables and the patterns of scorpion occurrence.

\section{Species classification}

Two groups could be distinguished in the classification of scorpion species on the basis of the quadrats where they occurred (Figures 6 and 7). The six Group A species had distributions that were peripheral to the study area-i.e. they occurred largely in coastal, northern and eastern parts of the study area and, in our data set, these species were predominantly at sandier sites. At least one of these species, Lychas sp. 8, is known to associate with sandy substrates (E.S. Volschenk unpublished data). The 11 Group B species were relatively widespread. Only species from Group B occurred at the cooler Group 4 sites from the site classification. Unfortunately, because little is known about the distribution and ecology of these species outside the study area, it is not possible to characterise these species groups further. 

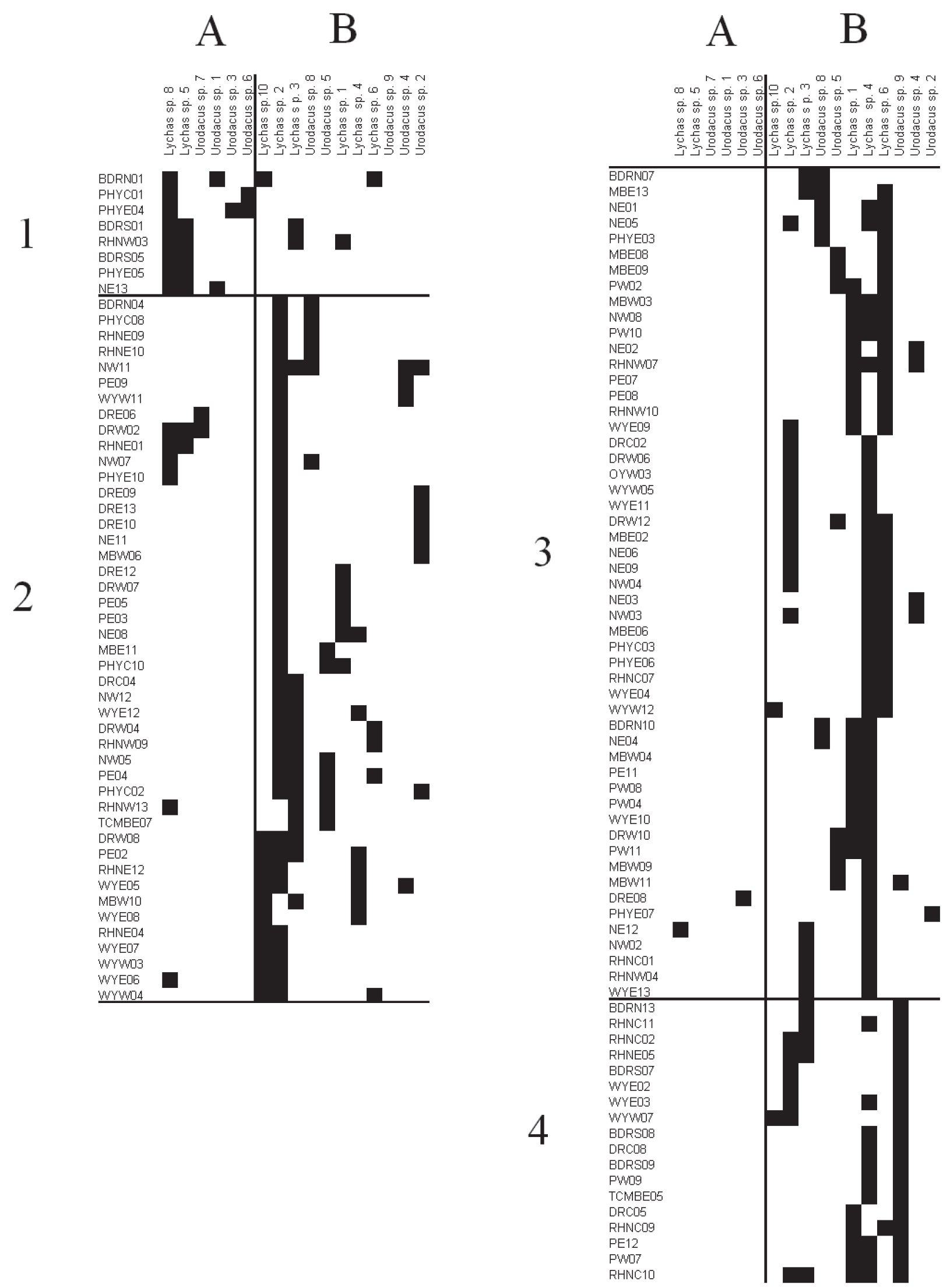

Figure 7 Data matrix of scorpion species re-ordered according to their co-occurrences at the same sites. The sites have been re-ordered according to similarities in their species composition. 


\section{DISCUSSION}

Almost all the 22 taxa that we encountered are undescribed, underlining the lack of knowledge of Australian scorpions, despite their likely importance in arid-zone guilds of small grounddwelling predators. This lack of knowledge also constrains the ecological interpretations that can be made. This study is therefore an exploratory one, and there is a need for much more data to be gathered from taxonomic, phylogenetic and ecological perspectives before we can draw firm conclusions about how these communities function.

Species richness per site in the Pilbara quadrats was less than that found in the Carnarvon Basin (Smith and McKenzie 2000), where richness varied from 0 to 6 species per site, with a mean of 3.1, compared with a range of 0 to 5 and a mean of 1.8 in the Pilbara. The Pilbara study area is a little over twice the size of the Carnarvon Basin study area, but more species were trapped in the Pilbara survey: 22 compared with 10. In the Carnarvon Basin survey, one bothriurid (Cercophonius granulosus) was trapped, plus five buthids (three species of Lychas and two species of Isometroides) and four urodacids (Urodacus spp). In contrast, in the Pilbara no bothriurids were recorded, but we did trap 10 species of Lychas, two of Isometroides and 10 species of Urodacus.

This discrepancy may partially be the result of differing taxonomic interpretation and species concepts used in these surveys. Smith and McKenzie (2000) attempted to use the key of L.E. Koch (1977) to identify Urodacus species. The species concept adopted by Koch supported highly variable species over wide ranges. This is distinctly different from that of the phylogenetic species concept which we adopt here, in which consistent somatic characters are interpreted as indicators of unique species, the same characters that Koch interpreted as acceptable variation in widespread species. Smith and McKenzie (2000) identified three groups within the species $U$. armatus Pocock. Recent studies (E.S. Volschenk unpublished obs.) indicate that $U$. armatus does not occur in the Carnarvon Basin and the three morphological groups identified within $U$. armatus are likely to represent three species.

Another factor compounding this discrepancy is site selection. Cercophonius was not found during the Pilbara survey, while Smith and McKenzie (2000) documented two individuals of one species from the Carnarvon Basin. The sole record of a species of Cercophonius from the Pilbara is a single specimen (WAM T65816) from Coppin Gap, on Yarrie Station. If Cercophonius is present elsewhere in the Pilbara, then it is most likely in the deep, cooler, more mesic gorges within the Hamersley Range. These gorges have potential to support relictual taxa including Cercophonius and the absence of this genus from this survey cannot be interpreted as absence from the Pilbara region since these gorges were not surveyed. This survey revealed nine undescribed Urodacus species, and one specimen of $U$. megamastigus. We did not record an additional species known to EV from two locations in the Hamersley and Chichester Ranges. Urodacus megamastigus is now known from several locations in the Fortescue Plain (E.S. Volschenk, unpublished obs.). These limitations, as well as the weak correlation with broad-scale environmental variables, indicate that a more finegrained approach to sampling and recording of environmental parameters may be needed to gain better understanding of Urodacus. This may also indicate that Smith and McKenzie (2000) might have underestimated species diversity in Urodacus in the Carnarvon Basin.

Scorpion assemblages in the Pilbara show only weak correlations with environmental variables, at least at the scales utilised in our study. This could be because our sampling was weak, as we only had five pit traps at each site, and therefore at some sites we may not have sampled the full range of micro-habitats utilised by scorpions. In particular, we may have missed sedentary species with narrow habitat requirements (Smith 1995; Smith and McKenzie 2000). In addition, our sampling methods were passive, and no active searching was carried out. Our data might not, therefore, provide an accurate picture of the environmental envelope of any given species, its geographic distribution within the Pilbara, or its community relationships. Another issue is that the environmental variables were chosen to be used across a range of biotic groups, from perennial plants to medium sized vertebrates and a range of invertebrate groups (McKenzie et al. 2009) and some would have been measured at a scale that may not be appropriate for scorpions. Because scorpions have low metabolic rates (Withers and Smith 1993), often burrow into sites where the ambient conditions are relatively constant and display primarily nocturnal activity patterns (Polis et al. 1986; Polis 1990; Brownell and Polis 2001; Brown et al. 2002), they may be to some extent independent of seasonal vicissitudes and the variables that we measured. One consequence of these factors is that Pilbara scorpions appear to be habitat generalists at the scale of resolution of our quadrats, a conclusion also drawn for similar reasons for scorpions in the Carnarvon Basin (Smith and McKenzie 2000). On the other hand, our traps were open for a year, and so we would have sampled through a broad range of seasonal and weather conditions likely to be encountered, thus optimising the likelihood of catching any scorpions that could be active under 
any of these circumstances. However, as we did not collect weather data from individual sites, we do not know whether our sampling has captured important weather events at the site level.

The land surface in the Pilbara is generally harder and rockier than in the Carnarvon Basin (Burbidge et al. 2000; McKenzie et al. 2009), and this may explain the apparently lower species richness at the site level-it may be that the Pilbara landscape is generally less favourable for scorpions than less rocky regions, or it may be that our trapping techniques were less efficient in rocky areas. The apparent scarcity of scorpions in Hamersley uplands (Figure 3) may be a reflection of this, as this area is the highest and hardest in the Pilbara. If sites suitable for scorpions are indeed small and patchily distributed in the Pilbara, then this may also have led to increased speciation by isolation, and hence to the apparently high regional diversity that we observed compared with the Carnarvon Basin.

Although some authors have suggested that temperature and rainfall influence scorpion diversity at broad geographical scales (Koch 1977; Polis 1990), we did not find strong evidence for this at the scale of the Pilbara bio-region. In our data set, ruggedness and edaphic parameters (soil depth, texture and nutrient status) were more strongly correlated with broad-scale patterns evident in the classification analysis, although the BEST analysis identified annual temperature as one of the five most important parameters contributing to the correlation between our biotic and abiotic matrices. Although we did not find tight correlations with environmental variables, the variables that did emerge from our analyses suggest that substrate and edaphic variables may exert some influence over scorpion distribution patterns in the Pilbara at relatively local scales. This is consistent with outcomes from a range of other studies (e.g. Lamoral 1978; Polis 1990; Locket 1993; Smith and McKenzie 2000). The interpretation of these kinds of data can be complicated, however, because scorpions are actually part of a larger guild of small grounddwelling carnivores and there may be an array of metacommunity interactions between scorpions and other macro-invertebrates and small reptiles that we did not consider in our analyses (Polis and Strong 1996; Spiller and Schoener 1998; Smith and McKenzie 2000; Ayal 2007).

Given that a number of these species may have distributions that extend well beyond the Pilbara, a better understanding of the biology and ecology of Pilbara scorpions is required before we can make informed recommendations for the conservation of these species.

\section{ACKNOWLEDGEMENTS}

Major funding for this project was provided by the WA Department of Environment and Conservation, with contributions from the Western Australian Museum, the Commonwealth Government (through the Natural Heritage Trust [NHT2]) and Straits Resources. Substantial in-kind support was also provided by Rio Tinto Iron Ore, BHP Billiton Iron Ore and Kitchener Mining (Bamboo Creek Operation).

We gratefully acknowledge the numerous Pilbara pastoralists and Aboriginal communities for permission to access their leases and/or land. We would like to thank the managers of the following pastoral stations for access to areas under their management: Bonney Downs, Coolawanyah, Corunna Downs, Glen Florrie, Hillside, Karratha, Mallina, Marillana, Mardie, Mount Florance, Mount Stuart, Mount Welcome, Mulga Downs, Munda, Mundabullangana, Nanutarra, Roy Hill, Sherlock, Uaroo, Warrawagine and Wyloo. In particular, Robyn and Tony Richardson of Mt Florance Station provided free access to their camping ground for the survey site installation and sampling teams and Rio Tinto Iron Ore provided access to subsidised housing for the first installation team while operating out of Karratha.

DEC Pilbara Region and National Park staff at Karratha and at Karijini and Millstream-Chichester National Parks provided subsidised accommodation for site installation and sampling teams, and the Department of Water provided access to Tabletop Hill, Harding Dam and sites along the West Pilbara water supply pipeline. Rio Tinto Iron Ore and BHP Billiton Iron Ore are acknowledged for permission to enter their exploration leases and for granting access to their rail access roads.

Several people assisted with sorting invertebrate specimens, with Nadine Guthrie having made a particular contribution. Jim Rolfe assisted with preparation of figures.

EV would also like to thank and acknowledge the Australian Biological Resources Study, Subterranean Ecology and Ecologia Environment for generous support to undertake this study, and Norman McKenzie for the invitation to contribute to this volume and for comments on the draft.

\section{REFERENCES}

Austin, M.P. (1991). Vegetation theory in relation to costefficient survey (pp 17-22). In: Margules, C.R. and Austin, M.P. (eds), Nature conservation: cost effective biological surveys and data analysis. CSIRO Division of Wildlife Ecology: Canberra, Australia.

Ayal, Y. (2007). Trophic structure and the role of predation in shaping hot desert communities. Journal of Arid Environments 68: 171-187. 
Beard, J.S. (1990). Plant life of Western Australia. Kangaroo Press: Kenthurst, NSW, Australia.

Belbin, L. (1993). PATN: pattern analysis package. CSIRO: Canberra, Australia.

Brown, C.A., Davis, J.M., O'Connell, D.J. and Formanowiz, D.R.J. (2002). Surface density and nocturnal activity in a west Texas assemblage of scorpions. Southwestern Naturalist 47: 409-419.

Brownell, P. and Polis, G.A. (eds) (2001). Scorpion biology and research. Oxford University Press: New York, U.S.A.

Burbidge, A.H., Harvey, M.S. and McKenzie, N.L. (eds) (2000). Biodiversity of the southern Carnarvon Basin. Records of the Western Australian Museum, Supplement 61.

Burbidge, A.H., Johnstone, R.E. and Pearson, D. (2010). Birds in a vast arid upland: avian biogeographical patterns in the Pilbara region of Western Australia. Records of the Western Australian Museum, Supplement 78: 247-270.

Burbidge, A.H., McKenzie, N., van Leeuwen, S., Gibson, L., Doughty, P., Guthrie, N., Durrant, B. and Pearson, D. (2006). Between rock and a hard place: rich biological patterns amongst ancient red rocks. Landscope 21 (3): 12-19.

Clarke, K.R. and Gorley, R.N. (2006). PRIMER v6: user manual/tutorial. PRIMER-E Ltd: Plymouth, U.K.

Clarke, K.R., Somerfield, P.J. and Chapman, M.G. (2006). On resemblance measures for ecological studies, including taxonomic dissimilarities and a zero-adjusted Bray-Curtis coefficient for denuded assemblages. Journal of Experimental Marine Biology and Ecology 330: 55-80.

Cracraft, J. (1983). Species concepts and speciation analysis (pp 159-187). In: Johnston, R.F. (ed.), Current ornithology. Plenum Press: New York, U.S.A., and London, U.K.

Cracraft, J. (1986). Origin and evolution of continental biotas: speciation and historical congruence within the Australian avifauna. Evolution 40: 977-996.

Cracraft, J. (1992). The species of the birds-of-paradise (Paradisaeidae): applying the phylogenetic species concept to a complex pattern of diversification. Cladistics 8: 1-43.

Department of Environment Water Heritage and the Arts (2009). Australia's bioregions. Department of Environment, Water Heritage and the Arts: Canberra, Australia; online at http://www.environment.gov. $\mathrm{au} /$ parks/nrs/science/ibra.html.

Dormann, C.F., McPherson, J.M., Araújo, M.B., Bivand, R., Bolliger, J., Carl, G., Davies, R.G., Hirzel, A., Jetz, W., Kissling, W.D., Kühn, I., Ohlemüller, R., Peres-Neto, P.R., Reineking, B., Schröder, B., Schurr, F.M. and Wilson, R. (2007). Methods to account for spatial autocorrelation in the analysis of species distributional data: a review. Ecography 30: 609-628.

Due, A.D. and Polis, G.A. (1986). Trends in scorpion diversity along the Baja California peninsula. American Naturalist 128: 460-468.

Durrant, B.J., Harvey, M.S., Framenau, V.W., Ott, R. and Waldock, J.M. (2010). Patterns in the composition of ground-dwelling spider communities in the Pilbara bioregion, Western Australia. Records of the Western Australian Museum, Supplement 78: 185-204.

Fet, V. and Lowe., G. (2000). Family Buthidae C.L. Koch, 1837 (pp 54-286). In: Fet, V., Sissom, W.D., Lowe, G. and Braunwalder, M.E. (eds), Catalogue of the scorpions of the world (1758-1998). New York Entomological Society: New York, U.S.A.

Fet, V., Polis, G.A. and Sissom, D.W. (1998). Life in sandy deserts: the scorpion model. Journal of Arid Environments 39: 609-622.

Guthrie, N.A., Weir, T. and Will, K. (2010). Localised and regional patterns in ground-dwelling beetle assemblages in a semi-tropical arid zone environment. Records of the Western Australian Museum, Supplement 78: 169-184.

Hadley, N.F. (1990). Environmental Physiology (pp 321-340). In: Polis, G.A. (ed.), The biology of scorpions. Stanford University Press: Stanford, U.S.A.

Harvey, M.S. (2002). Short-range endemism in the Australian fauna: some examples from non-marine environments. Invertebrate Systematics 16: 555-570.

Koch, L.E. (1970). Predation of the scorpion, Urodacus hoplurus, by the lizard, Varanus gouldi. Western Australian Naturalist 11: 120-121.

Koch, L.E. (1977). The taxonomy, geographic distribution and evolutionary radiation of Australo-Papuan scorpions. Records of the Western Australian Museum 5: 83-367.

Koch, L.E. (1981). The scorpions of Australia: aspects of their ecology and zoogeography (pp 873-884). In: Keast, A. (ed.), Ecological biogeography of Australia. Junk: The Hague, Netherlands.

Lamoral, B. (1978). Soil hardness, an important and limiting factor in burrowing scorpions of the genus Opistophthalmus C.L. Koch 1837 (Scorpionidae, Scorpionida). Symposium of the Zoological Society of London 42: 171-181.

Lamoral, B.H. (1979). The Scorpions of Namibia (Arachnida: Scorpionida). Annals of the Natal Museum 23: 497-784.

Leighton, K.A. (2004). Climate (pp 19-38). In: Van Vreeswyk, A.M.E., Payne, A.L., Leighton, K.A. and Hennig, P. (eds), An inventory and condition survey of the Pilbara Region, Western Australia. Technical Bulletin No. 92. Western Australian Department of Agriculture: Perth, Australia.

Levy, G., and Amitai, P. (1980). Fauna Palestina. Arachnida I. Scorpiones. Keterpress: Jerusalem, Israel.

Lighton, J.R.B., Brownell, P.H., Joos, B. and Turner, R.J. (2001). Low metabolic rate in scorpions: implications for population biomass and cannibalism. Journal of Experimental Biology 204: 607-613.

Locket, N.A. (1993). Scorpion distribution in a dune and swale mallee environment. Memoirs of the Queensland Museum 33: 593-598.

Main, B.Y. (1956). Taxonomy and biology of the genus Isometroides Keyserling (Scorpionida). Australian Journal of Zoology 4: 158-164.

Marples, T.G. and Shorthouse, D.J. (1982). An energy and water budget for a population of the arid zone scorpion Urodacus yaschenkoi (Birula 1903). Australian Journal of Ecology 7: 119-127. 
McKenzie, N.L., Belbin, L., Margules, C.R. and Keighery, G.J. (1989). Selecting representative reserve systems in remote areas: a case study in the Nullarbor region, Australia. Biological Conservation 50: 239-261.

McKenzie, N.L., van Leeuwen, S. and Pinder, A.M. (2009). Introduction to the Pilbara Biodiversity Survey, 2002-2007. Records of the Western Australian Museum, Supplement 78: 3-89.

McMahon, J.P., Hutchinson, M.F., Nix, H.A. and Ord, K.D. (1995). ANUCLIM users guide, version 1. Centre for Resource and Environmental Studies, Australian National University: Canberra, Australia.

Mello-Leitão, C. (1945). Escorpiões sul-americanos. Arquivos de Museu Nacional XL: 468.

Polis, G.A. (1990). Ecology (pp 248-293). In: Polis, G.A. (ed.), The biology of scorpions. Stanford University Press: Stanford, U.S.A.

Polis, G.A. (1991). Complex trophic interactions in deserts: an empirical critique of food-web theory. American Naturalist 138: 123-155.

Polis, G.A. (1993). Scorpions as model vehicles to advance theories of population and community ecology: the role of scorpions in desert communities. Memoirs of the Queensland Museum 33: 401-410.

Polis, G.A., Myers, C.A. and Quinlan, M.A. (1986). Burrowing biology and spatial distribution of desert scorpions. Journal of Arid Environments 10: 137-146.

Polis, G.A. and Strong, D.R. (1996). Food web complexity and community dynamics. American Naturalist 147: 813-846.

Ponder, W.F. and Colgan, D.J. (2002). What makes a narrow-range taxon? Insights from Australian freshwater snails. Invertebrate Systematics 16: 571-582.

Prendini, L. (2005). Scorpion diversity and distribution in southern Africa: pattern and process (pp 25-68). In: Huber, B.A., Sinclair, B.J. and Lampe, K.H. (eds), African biodiversity: molecules, organisms, ecosystems. Springer: New York, U.S.A.

Smith, G.T. (1966). Observations on the life history of the scorpion Urodacus abruptus Pocock (Scorpionidae) and an analysis of its home sites. Australian Journal of Zoology 14: 383-399.

Smith, G.T. (1991). Scorpions in Kimberley rainforests (pp 269-270). In: McKenzie, N.L., Johnston, R.B. and Kendrick, P.G. (eds), Kimberley rainforests. Surrey Beatty \& Sons: Chipping Norton, Australia.

Smith, G.T. (1995). Species richness, habitat and conservation of scorpions in the Western Australian wheatbelt. Records of the Western Australian Museum, Supplement 52: 55-66.

Smith, G.T. and McKenzie, N.L. (2000). Biogeography of scorpion communities in the southern Carnarvon Basin, Western Australia. Records of the Western Australian Museum, Supplement 61: 269-279.

Sneath, P.H.A. and Sokal, R.R. (1973). Numerical TAXONOMY: the principles and practice of numerical classification. Freeman: San Francisco, U.S.A.

Spiller, D.A. and Schoener, T.W. (1998). Lizards reduce spider species richness by excluding rare species. Ecology 79: 503-516.

Standen, V. (2000). The adequacy of collecting techniques for estimating species richness of grassland invertebrates. Journal of Applied Ecology 37: 884-893.

Taylor, J.A. and Friend, G.R. (1984). Sampling strategies for fauna surveys (pp 179-182). In: Myers, K., Margules, C.R. and Musto, I. (eds), Survey methods for nature conservation. CSIRO: Canberra, Australia.

Thackway, R. and Cresswell, I.D. (1995). An interim biogeographic regionalisation of Australia. Australian Nature Conservation Agency: Canberra, Australia.

Tikader, B.K. and Bastewade, D.B. (1983). Fauna of India; Scorpions, Scorpionida: Arachnida. Zoological Survey of India and Sangam Press Pvt Ltd: Calcutta, India.

Trendall, A.E. (1990). Pilbara Craton (pp 128-158). In: Geology and mineral resources of Western Australia. Memoir 3, Geological Survey of Western Australia: Perth, Australia.

Withers, P.C. and Smith, G.T. (1993). Effect of temperature on the metabolic rate and evaporative water loss of the scorpion Urodacus armatus. Journal of Thermal Biology 18: 13-18.

\section{APPENDIX 1.}

Table showing scorpion species collected at 294 quadrats in the Pilbara bioregion (note that we detected scorpions at only 235 quadrats, see text for details). Table data are presence/absence, with presence indicated by ' 1 '. Details of quadrats may be found in McKenzie et al. (2009).

See CD inside the back cover, or visit:

http://www.museum.wa.gov.au/research/records-supplements/attachments 